\title{
Surgical intervention for hydrocephalus in infancy; etiology, age and treatment data in a Dutch cohort
}

\author{
J. C. Holwerda ${ }^{1}$ (ID - E. J. van Lindert ${ }^{2}$ - D. R. Buis ${ }^{3} \cdot$ E. W. Hoving ${ }^{4}$. Dutch Pediatric Neurosurgery Study Group
}

Received: 11 June 2019 / Accepted: 28 July 2019 / Published online: 12 August 2019

(C) The Author(s) 2019

\begin{abstract}
Purpose To gain insight into the patient characteristics of surgically treated hydrocephalus in the Netherlands, we report the first data from the Dutch Quality Registry NeuroSurgery (QNRS) database for infants with hydrocephalus requiring surgical intervention.

Methods We used the prospectively gathered database concerning infants $\leq 2$ years of age surgically treated for hydrocephalus. We report data from start of registry, concerning etiology, age, and treatment of patients registered. We compared data with the Hydrocephalus Clinical Research Network (HCRN), a multicenter network of pediatric neurosurgical institutions in North America.

Results A total of 359 operated infants was registered in the period from 2010 to 2017. A drop in patients registered was seen in 2015, possibly due to revisions of the database. Most infants were operated on between 1 and 6 months of age. Cause of hydrocephalus was predominantly intracranial hemorrhage, followed by congenital causes. The proportion of infants with aqueduct stenosis and myelomeningocele as cause of hydrocephalus stayed relatively stable during this period of registration. Initial shunting was performed in $40 \%$ and reservoir/ETV as initial treatment was done in $60 \%$. In both groups, $50 \%$ needed revision surgery.

Conclusions The first data concerning surgically treated pediatric hydrocephalus from a prospectively collected Dutch register are presented, showing similar results when comparing to the HCRN database.
\end{abstract}

Keywords Fetal cerebral ventriculomegalies · Hydrocephalus · Hydrocephalus congenital · Hydrocephalus etiology · Neurosurgery $\cdot$ Pediatrics $\cdot$ Surgical procedures $\cdot$ Operative $\cdot$ Registries

\section{Abbreviations}

QNRS Dutch Quality Registry Neurosurgery

CSF Cerebrospinal fluid

HCRN Hydrocephalus Clinical Research Network

NVvN Dutch Society of Neurosurgery

J. C. Holwerda

j.c.holwerda@umcg.nl

1 Department of Pediatrics, Division of Neonatology, Beatrix Children's Hospital/University Medical Center Groningen, Hanzeplein 1, 30.001, 9700 RB Groningen, The Netherlands

2 Department of Neurosurgery, Radboud University Medical Center Nijmegen, Nijmegen, The Netherlands

3 Department of Neurosurgery, Amsterdam University Medical Center, Amsterdam, The Netherlands

4 Department of Neurosurgery, University Medical Center Utrecht, Utrecht, The Netherlands
MMC Myelomeningocele

ETV Endoscopic third ventriculostomy

\section{Introduction}

To elucidate the effectiveness of treatment and patient outcome after neurosurgery several clinical registries have emerged in Europe and North America [1-4]. These registries have proven to be valuable tools to evaluate quality of care [4], and may be a means to compare effectiveness between methods and treatment centers.

The Dutch Society of Neurosurgery maintains a quality registry for neurosurgical procedures carried out in the 19 neurosurgical clinics in the Netherlands, the Quality Registry of Neurosurgery (QRNS). Four neurosurgical illnesses are structurally registered: subarachnoid hemorrhage, glioblastoma multiforme, pituitary adenoma, and hydrocephalus in 
children $\leq 2$ years of age. Hydrocephalus in infants and young children is only treated in the neurosurgical clinics of the eight university hospitals. Shunt implantation, ventricular access device implantation, and endoscopic third ventriculostomy are registered.

In young infants, the incidence of hydrocephalus has been estimated to range from 2.0 to 8.1 per 1000 live births [5-10]. This wide range in incidence is partly due to the variety of definitions being used, either with or without surgical intervention, with or without trauma, and partly because registration took place over different time-periods and in different countries. A thorough investigation of the incidence of congenital hydrocephalus in four regions in Europe did not include details about etiology [5]. The epidemiology and incidence of infantile hydrocephalus requiring surgical intervention has not been systematically reported in the European population, and details about shunting outcome have been published from single centers only $[11,12]$.

Shunt dysfunction with subsequent shunt revisions are common problems in infants. Most shunt dysfunctions occur at a young age and decrease with age [13]. Systematically obtained information about etiology and shunt dysfunction might give insight into the process of shunt dysfunction in young infants. A study of the Hydrocephalus Clinical Research Network (HCRN), a multicenter network of pediatric neurosurgical institutions in North America [14], compared their clinical data registry to a historical cohort. They reported a reduction in the risk for time to first shunt failure in children until 19 years of age. A cause or relation with etiology for this reduction could not be clearly identified, but was hypothesized to be a combination of differences in diagnosis of shunt failure, patient selection, baseline characteristics, practice patterns, and interval to follow-up.

To elucidate the etiology of surgically treated infantile hydrocephalus in a Dutch population, we investigated the Dutch QRNS database for infants with hydrocephalus requiring surgical intervention. We report the first time-period of registration, from the years 2010-2017, in order to evaluate the registration implementation and to study possible shifts in surgical practice patterns. Also we compared our findings with the cohorts studied in North America and Canada. We aim to report etiology, age at intervention, and first treatment data with prospectively gathered data. This will be the first presentation of data since initiation of the QRNS for surgically treated hydrocephalus.

\section{Methods}

\section{Population}

The data we present is derived from the QRNS, the systematic database of the Dutch Society of Neurosurgery $(\mathrm{NVvN})$ in collaboration with the Stichting Informatievoorziening Zorg (SIVZ), a nationwide institute concerned with the registration and data handling of healthcare institutes in the Netherlands. In the QNRS database all patients treated for subarachnoid hemorrhage, glioblastoma multiforme, pituitary adenoma, and hydrocephalus in children under 2 years of age in the Netherlands are registered, with details concerning diagnosis, treatment and follow-up. We gathered the data of patients born between 2010 and 2017 who were surgically treated for hydrocephalus within in the first 2 years of life. Date of diagnosis, as entered into the database, was used as date of registration. Data was collected for first intervention and revision, if revision was necessary.

Patients were treated at 1 of 8 dedicated pediatric neurosurgical centers (Academic Medical Center Amsterdam, Leiden University Medical Center; VU University Medical Center Amsterdam; University Medical Center Utrecht; Maastricht University Medical Center; Radboud University Medical Center Nijmegen; Erasmus University Medical Center Rotterdam; University Medical Center Groningen, the Netherlands).

We report data from birth years 2010 through 2017. Permission to use data was granted for each participating center. Data were anonymized before analyses, and local ethical research protocol for data collection was adhered to for the QNRS.

We compared data concerning age at intervention and etiology of hydrocephalus with the cohort published by the Hydrocephalus Clinical Research Network (HCRN) [14]; a multicenter network of 7 pediatric neurosurgical institutions in North America. This cohort consists of prospectively collected data of patients $\leq 19$ years, surgically treated for hydrocephalus between 2008 and 2012. As follow-up of children differed per center, it was assumed that the absence of followup data means no shunt revision took place.

\section{Definitions}

Etiology of hydrocephalus was determined in the QRNS database as either aqueductal stenosis, hemorrhage (due to prematurity and other causes), cerebrospinal fluid infection (meningitis/ventriculitis/encephalitis), tumor (all types), myelomeningocele (MMC), congenital, miscellaneous, or unknown. The miscellaneous group included intracranial cysts, posterior fossa cysts, and craniosynostosis.

\section{Statistics}

We used Predictive Analytic Software (PASW) 18.0 for Windows by SPSS (SPSS Inc., Chicago, IL) for data analyses. 


\section{Results}

\section{Population}

From 2010 to 2017, 359 patients were registered for surgery of hydrocephalus in the first 2 years of life. In 10 patients, data on treatment was incomplete and kept out of analyses. Registration showed an upward trend with a peak in 2013, followed by a decrease for 2015 and 2016. Table 1 shows patients characteristics of total and per year of registration. Of the total 349 patients, more patients were male (53\%), this being consistent for each separate year of registration. As seen in Fig. 1, hemorrhage was leading diagnosis for surgical treatment in almost every year, followed by congenital hydrocephalus (resp. 42 and $22 \%$ in total group). The proportion of infants with aqueduct stenosis and MMC as underlying cause stayed stable over the years registered. In 2015 the proportion of unknown etiology showed a sudden increase, being $25 \%$ of total registered patients. For the years 2015 and 2016, tumorrelated hydrocephalus was not reported.

Most children were operated between 1 month after birth and before they reached 6 months of age, a consistent finding when looking at the separate years as well as in the total group (Fig. 2).

In 136 (39\% of total) patients, initial treatment was Ommaya/Rickham reservoir placement, in 59 (17\%), ETV and $12(3 \%)$ were categorized as other (temporary external drains/serial lumbar punctures) (Fig. 3). In 141 (40\%) patients, a shunt was placed directly. In one patient, ventriculoperitoneal shunt placement and ETV were combined. Revision was needed for $71(52 \%)$ infants of the Ommaya/Rickham cohort, 28 $(48 \%)$ in the ETV group, and $6(50 \%)$ in the group of serial punctures. Of the 141 shunts placed directly at diagnosis,
$70(50 \%)$ needed revision, and $71(50 \%)$ did not. The patient treated with shunt and ETV simultaneously did not need revision. The specifics of the revisions performed were not included in the database, so whether revisions being shunt insertion, shunt explantation, or re-ETV is unknown.

\section{Discussion}

This paper reports the first data concerning pediatric hydrocephalus registered in the QRNS, the systematic database of the Dutch Society of Neurosurgery (NVvN). With the importance of structural multicenter registration of surgical intervention being shown in registries from the USA and Canada [14], this is the first report from a prospectively collected nationwide European registry concerning pediatric hydrocephalus.

The number of registered patients shows a peak in 2013. This peak might be due to the more structural use of the registry and the improved implementation of the database. It is not likely that such in increase can be accounted to patient increase alone, and it is known that the implementation and widespread use of a registry will take some time [4]. The decrease in patient numbers in the registry from 2014 onward might be accounted to the introduction of a new improved database format, causing a pause in data input.

Gender distribution among registered patients was identical over the years, with male predominance. This is consistent with previous reports, showing a larger proportion of male pediatric hydrocephalic patients [15-17]. The reason for male predominance in the hydrocephalic pediatric patient population is still not accounted for, so far only a possible difference in normal values of ventricle size between genders has been described [18].

Table 1 Patient characteristics and annual distribution of the QNRS cohort of patients registered for surgical intervention of hydrocephalus under the age of 2 years

\begin{tabular}{|c|c|c|c|c|c|c|c|c|}
\hline & Total & 2010 & 2011 & 2012 & 2013 & 2014 & 2015 & 2016 \\
\hline $\begin{array}{l}\text { Patients registered } \\
\text { (\% of total) }\end{array}$ & 349 & $4(1)$ & $38(11)$ & $51(15)$ & $89(26)$ & $85(24)$ & $56(16)$ & $22(6)$ \\
\hline Male/female ( $\%$ of total) & $186(53) / 139(40)$ & $3(75) / 1(25)$ & $23(61) / 15(39)$ & $28(55) / 23(45)$ & $48(54) / 40(45)$ & $51(60) / 34(40)$ & $24(43) / 18(32)$ & $8(36) / 5(23)$ \\
\hline \multicolumn{9}{|l|}{ Etiology (\% of group) } \\
\hline Hemorrhage & $145(42)$ & $1(25)$ & $12(32)$ & $18(35)$ & $37(42)$ & $38(45)$ & $29(52)$ & $10(46)$ \\
\hline Congenital & $76(22)$ & $2(50)$ & $13(34)$ & $10(20)$ & $25(28)$ & $17(20)$ & $4(7)$ & $4(18)$ \\
\hline Myelomeningocele & $32(9)$ & $1(25)$ & $4(11)$ & $4(8)$ & $7(8)$ & $6(7)$ & $8(14)$ & $2(9)$ \\
\hline Aquaduct stenosis & $30(9)$ & 0 & $2(5)$ & $4(8)$ & $5(6)$ & $12(14)$ & $5(9)$ & $2(9)$ \\
\hline Tumor & $22(6)$ & 0 & $4(11)$ & $4(8)$ & $6(7)$ & $5(6)$ & 0 & 0 \\
\hline $\begin{array}{l}\text { Cerebrospinal fluid } \\
\text { infection }\end{array}$ & $18(5)$ & 0 & $2(5)$ & $5(10)$ & $2(2)$ & $6(7)$ & $2(4)$ & $1(5)$ \\
\hline Miscellaneous & $16(5)$ & 0 & $1(3)$ & $5(10)$ & $6(7)$ & $1(1)$ & $1(2)$ & $2(9)$ \\
\hline Unknown & $10(3)$ & 0 & 0 & $1(2)$ & $1(1)$ & 0 & $7(13)$ & $1(5)$ \\
\hline \multicolumn{9}{|c|}{ Age at surgical intervention (\% of group) } \\
\hline$<1$ st month & $94(27)$ & 0 & $11(29)$ & $11(22)$ & $31(35)$ & $22(26)$ & $14(25)$ & $5(23)$ \\
\hline 1 to $<6$ months & $152(44)$ & $4(100)$ & $18(48)$ & $24(47)$ & $35(40)$ & $42(50)$ & $22(40)$ & $7(32)$ \\
\hline 6 to $<12$ months & $44(13)$ & 0 & $8(21)$ & $10(20)$ & $7(8)$ & $14(17)$ & $4(7)$ & $1(5)$ \\
\hline $12-24$ months & $35(10)$ & 0 & 1(3) & $6(12)$ & $15(17)$ & $7(8)$ & $2(4)$ & 0 \\
\hline
\end{tabular}


Fig. 1 Proportions of the etiologies of surgically intervened hydrocephalus for total and separate years of registration

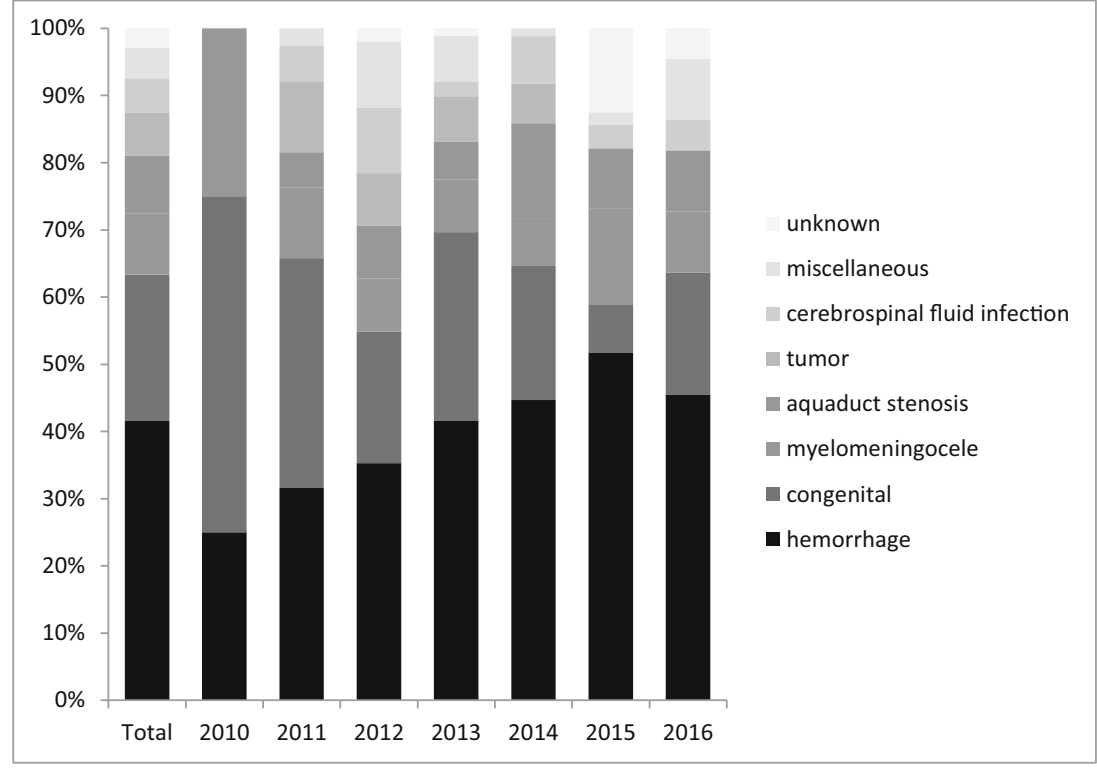

The first intervention most often took place in children aged $\leq 6$ months (44\%). In the group of the Hydrocephalus Clinical Research Network Registry [14], the biggest proportion of children operated on was also at age between 1 and 6 months. The overall percentage, $30 \%$, was lower, but that might be explained by the difference in inclusion criteria, being until age 19, in comparison with our group until 2 years of age. Reason for this peak in age at operation might be the underlying cause of the hydrocephalus, being mostly hemorrhage and congenital cause, together accounting for $64 \%$ of the group. After hemorrhage, a posthemorrhagic ventricular dilatation (PHVD) occurs mostly in preterm born babies, with low birth weight. The subsequent hydrocephalus develops over time and is in the Netherlands preferably initially treated with serial lumbar punctures or serial punctures from a ventricular access device (Ommaya/Rickham reservoir) [19]. This way, an infant is more likely to be $>1$ month of age. When looking at both causes of hydrocephalus separately, the largest percentage of children with hemorrhage (49\%) and congenital causes $(46 \%)$ was operated on in the period between 1 and 6 months of age.

The percentage of infants who needed surgical intervention due to aqueduct stenosis ( $9 \%$ of total) stayed more or less stable over the years of registration. Aqueduct stenosis represented $8 \%$ in the American/Canadian group. The incidence of aqueduct stenosis shows a consistency in the Western world $[20,21]$.

Compared with the Dutch database, a larger percentage of MMC was reported in the HCRN database (9\% vs $16 \%$ ). This might be due to the larger percentage of termination of
Fig. 2 Distribution of age at first intervention

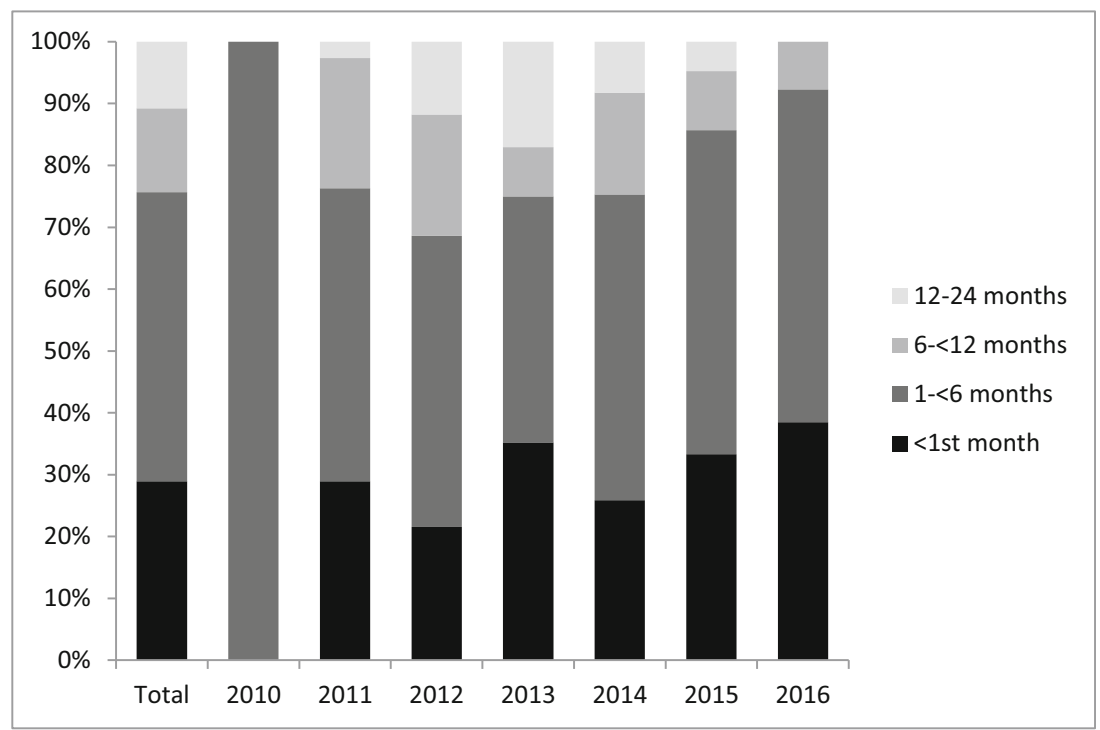




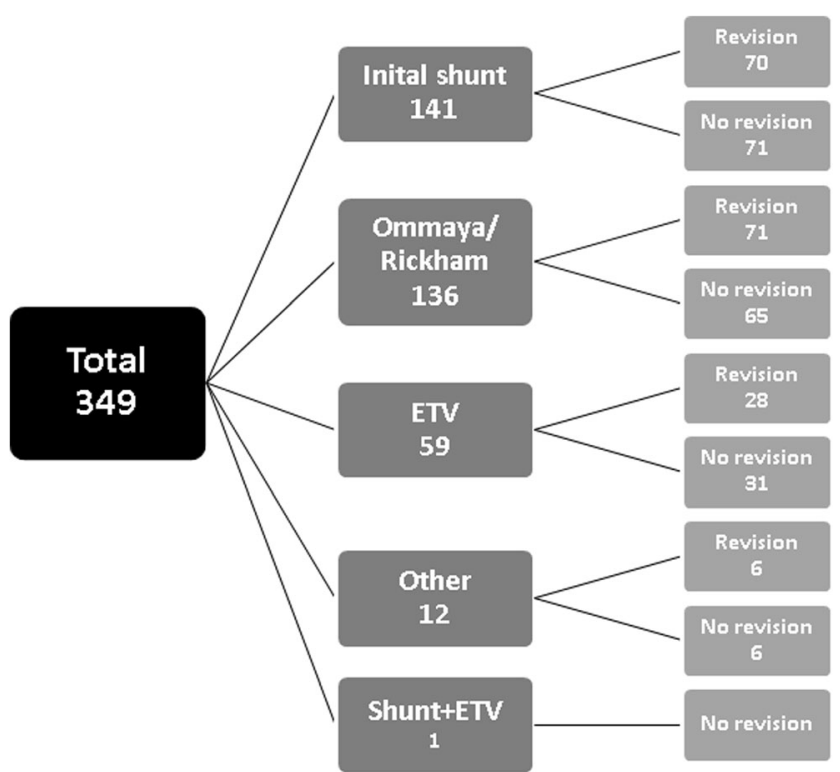

Fig. 3 Flowchart representing numbers of infants treated with shunt, Ommaya/Rickham reservoir, third ventriculostomy (ETV) or other, and numbers on necessity of revision

pregnancies for $\mathrm{MMC}$ in the Netherlands in comparison to the HCRN cohort [18], due to the introduction of the structural prenatal ultrasound offered to all pregnant women in the Netherlands since 2007. In the HCRN database, the incidence of MMW as etiology showed a decrease when compared with a historical cohort, possibly due to the introduction of food fortification with folic acid [22].

The sudden decrease of tumor-based hydrocephalus might be caused by the reformatting of the database in this period in combination with a centralization of pediatric oncological care in the Netherlands. The difference in tumor as underlying cause of hydrocephalus between the Dutch and HCRN database (6\% versus $18 \%)$ is most likely explained by the differences in ages included in the databases [23]. The proportion of CSF infection as a cause for surgery is approximately the same in both groups.

The collected data concerning treatment method showed that in 141 infants (40\% of total group) a shunt was placed directly. In this group, there was a $50 \%$ chance for the need of revision. Of the remaining 207 infants $(60 \%$, not taking into account 1 infant with shunt and ETV combined), 105 (51\%) needed revision. In all treatment groups, the chance of revision was about $50 \%$. The specifics of the revisions performed were not included in the database, so whether revisions being shunt insertion, shunt explantation, or re-ETV are unknown. Studies into survival rates have shown better ETV survival in young infants ( $<6$ months of age) with aquaduct stenosis, and worse survival rates in children with MMC, hemorrhage or infection, and different success rates of re-ETV or shunt placement [24-26]. These data, not included in our study, should be reported in future studies to compare success rate of surgery and outcome data of our surgical experience with other databases [19, 24].

When looking at our results, the limitations of our study should be taken into account. Due to the new implementation of the database, start-up problems causing incomplete data are widespread. The separate centers handled registration differently, and the database was revised more than once, causing gaps in data entry. For the purpose of this analysis, it was assumed that the absence of follow-up data means no shunt revision took place. In the Netherlands, shunt surgery in children only takes place in 8 university hospitals; therefore, it is highly unlikely that revisions were not entered into the database. But even though the limitations of the study, the usefulness of a database concerning surgically treated hydrocephalus, also for future study, has been presented.

\section{Conclusion}

We present the first prospectively collected multicenter data of a European based national registry for surgically intervened pediatric hydrocephalus in the first 2 years of life, over the period 2010-2017. Our data show that most infants are surgically treated for hydrocephalus are between 1 and 6 months of age, and concerning the etiology the proportion of posthemorrhagic and congenital causes are most frequently seen. In $40 \%$ of infants, treatment was initial shunt placement, versus $60 \%$ of infants treated with reservoir, ETV or taps. Revision percentage was $50 \%$ for each treatment method. Our findings concerning etiology and age at treatment show similarity when compared with a large North American registry.

Acknowledgements We would like to thank the Dutch Neurosurgical Society $(\mathrm{NVvN})$ and the Dutch Pediatric Neurosurgical Study Group for kindly permitting the use of the data registered in the Dutch Quality Registry Neurosurgery. We would like to express our gratitude for the help received from the Stichting Informatievoorziening Zorg (SIVZ, https://www.sivz.nl/nl/projecten/qrns).

Funding This study was supported by the Junior Scientific Masterclass, Groningen, the Netherlands.

\section{Compliance with ethical standards}

Conflict of interest The authors declare that they have no conflict of interest.

Open Access This article is distributed under the terms of the Creative Commons Attribution 4.0 International License (http:// creativecommons.org/licenses/by/4.0/), which permits unrestricted use, distribution, and reproduction in any medium, provided you give appropriate credit to the original author(s) and the source, provide a link to the Creative Commons license, and indicate if changes were made. 


\section{References}

1. O'Kane M, Richards H, Winfield P, Pickard J (1997) The United Kingdom shunt registry. Eur J Ped Surg 7:56

2. McGirt MJ, Speroff T, Dittus RS, Harrell FE Jr, Asher AL (2013) The national neurosurgery quality and outcomes database (N2QOD): general overview and pilot-year project description. Neurosurg Focus 34(1):E6

3. Kolias AG, Bulters DO, Cowie CJ, Wilson MH, Afshari FT, Helmy A, Broughton E, Joannides AJ, Zebian B, Harrisson SE, Hill CS, Ahmed AI, Barone DG, Thakur B, McMahon CJ, Adlam DM, Bentley RP, Tolias CM, Mitchell PM, Whitfield PC, Critchley GR, Belli A, Brennan PM, Hutchinson PJ, British Neurosurgical Trainee Research Collaborative, British Neurotrauma Group, UKCRR Collaborative Group (2014) Proposal for establishment of the UK cranial reconstruction registry (UKCRR). Br J Neurosurg 28(3):310-314

4. Asher AL, Parker SL, Rolston JD, Selden NR, McGirt MJ (2015) Using clinical registries to improve the quality of neurosurgical care. Neurosurg Clin N Am 26(2):253-263 ix-x

5. Garne E, Loane M, Addor MC, Boyd PA, Barisic I, Dolk H (2010) Congenital hydrocephalus-prevalence, prenatal diagnosis and outcome of pregnancy in four european regions. Eur J Paediatr Neurol 14(2): $150-155$

6. Stein SC, Guo W (2009) The prevalence of shunt-treated hydrocephalus: a mathematical model. Surg Neurol 72(2):131-137

7. Persson EK, Anderson S, Wiklund LM, Uvebrant P (2007) Hydrocephalus in children born in 1999-2002: epidemiology, outcome and ophthalmological findings. Childs Nerv Syst 23(10): $1111-1118$

8. Green AL, Pereira EA, Kelly D, Richards PG, Pike MG (2007) The changing face of paediatric hydrocephalus: a decade's experience. $\mathrm{J}$ Clin Neurosci 14(11):1049-1054

9. Persson EK, Hagberg G, Uvebrant P (2005) Hydrocephalus prevalence and outcome in a population-based cohort of children born in 1989-1998. Acta Paediatr 94(6):726-732

10. Chumas P, Tyagi A, Livingston J (2001) Hydrocephalus- what's new? Arch Dis Child Fetal Neonatal Ed 85:F149-F154

11. Heinsbergen I, Rotteveel J, Roeleveld N, Grotenhuis A (2002) Outcome in shunted hydrocephalic children. Eur J Paediatr Neurol 6(2):99-107

12. Brouwer AJ, van Stam C, Uniken Venema M, Koopman C, Groenendaal F, de Vries LS (2012) Cognitive and neurological outcome at the age of 5-8 years of preterm infants with posthemorrhagic ventricular dilatation requiring neurosurgical intervention. Neonatology 101(3):210-216

13. Richards HK, Seeley HM, Pickard JD (2009) Efficacy of antibioticimpregnated shunt catheters in reducing shunt infection: data from the United Kingdom shunt registry. J Neurosurg Pediatr 4(4):389393

14. Kulkarni AV, Riva-Cambrin J, Butler J, Browd SR, Drake JM, Holubkov R, Kestle JRW, Limbrick DD, Simon TD, Tamber MS, Wellons JC, Whitehead WE (2013) Outcomes of CSF shunting in children: comparison of hydrocephalus clinical research network cohort with historical controls: Clinical article. J Neurosurg Pediatr 12(4):334-338

15. Drake JM (2007) Canadian pediatric neurosurgery study group. Endoscopic third ventriculostomy in pediatric patients: the Canadian experience. Neurosurgery 60(5):881-886 discussion 881-6

16. Brouwer AJ, Groenendaal F, Han KS, de Vries LS (2015) Treatment of neonatal progressive ventricular dilatation: a singlecentre experience. J Matern Fetal Neonatal Med 28(Suppl 1):22732279

17. Preuss M, Kutscher A, Wachowiak R, Merkenschlager A, Bernhard MK, Reiss-Zimmermann M, Meixensberger J, Nestler U (2015) Adult long-term outcome of patients after congenital hydrocephalus shunt therapy. Childs Nerv Syst 31(1):49-56

18. Robroch B, Holwerda J, Bos AF, Bilardo CM, van den Berg PP, Snijders RJ (2013) Ventriculomegaly at the gestational age of 20 weeks; research into its incidence and related abnormalities. Ned Tijdschr Geneeskd 157(3):A5148

19. Leijser LM, Miller SP, van Wezel-Meijler G, Brouwer AJ, Traubici J, van Haastert IC, Whyte HE, Groenendaal F, Kulkarni AV, Han KS, Woerdeman PA, Church PT, Kelly EN, van Straaten HLM, Ly LG, de Vries LS (2018) Posthemorrhagic ventricular dilatation in preterm infants: when best to intervene? Neurology. 90(8):e698 e706

20. Hirsch JF, Hirsch E, Sainte Rose C, Renier D, Pierre-Khan A (1986) Stenosis of the aqueduct of sylvius. Etiology and treatment. J Neurosurg Sci 30(1-2):29-39

21. Robertson IJ, Leggate JR, Miller JD, Steers AJ (1990) Aqueduct stenosis-presentation and prognosis. Br J Neurosurg 4(2):101-106

22. Atta CA, Fiest KM, Frolkis AD et al (2016) Global birth prevalence of spina bifida by folic acid fortification status: a systematic review and meta-analysis. Am J Public Health 106(1):e24-e34

23. Ostrom QT, Gittleman H, Fulop J, Liu M, Blanda R, Kromer C, Wolinsky Y, Kruchko C, Barnholtz-Sloan JS (2015) CBTRUS statistical report: primary brain and central nervous system tumors diagnosed in the United States in 2008-2012. Neuro-Oncology 17(Suppl 4):iv1-iv62

24. Breimer GE, Dammers R, Woerdeman PA, Buis DR, Delye H, Brusse-Keizer M, Hoving EW, Dutch Pediatric Neurosurgery Study Group (2017) Endoscopic third ventriculostomy and repeat endoscopic third ventriculostomy in pediatric patients: the dutch experience. J Neurosurg Pediatr 20(4):314-323

25. Duru S, Peiro JL, Oria M, Aydin E, Subasi C, Tuncer C, Rekate HL (2018) Successful endoscopic third ventriculostomy in children depends on age and etiology of hydrocephalus: outcome analysis in 51 pediatric patients. Childs Nerv Syst 34(8):1521-1528

26. Moreira I, Pereira J, Oliveira J, Salvador SF, Vaz R (2016) Endoscopic re-opening of third ventriculostomy: case series and review of literature. Clin Neurol Neurosurg 145:58-63

Publisher's note Springer Nature remains neutral with regard to jurisdictional claims in published maps and institutional affiliations. 